\title{
Comparison of death anxiety and state-trait anxiety levels in mothers of disabled children and non-disabled children
}

\author{
Adile Koca $^{1 \oplus}$, Saziye Senem Basgul ${ }^{1 \oplus}$, Mahmut Yay ${ }^{1 \odot}$ \\ ${ }^{1}$ Hasan Kalyoncu University, Faculty of Medicine, Department of Psychology, Gaziantep - Turkey
}

\begin{abstract}
Objective: This study aims to investigate the death anxiety and state-trait anxiety levels of mothers of disabled children and compare them with mothers of non-disabled children. Data obtained from this study will contribute to the planning of services provided to families of children with disabilities.

Method: The sample group consisted of 80 mothers of disabled children attending rehabilitation and special education centers in the province of Gaziantep and 78 mothers of non-disabled children, 158 mothers in total. The study used a convenience sampling method. A sociodemographic information form, Abdel-Khalek's Arabic Scale of Death Anxiety (ASDA), and the StateTrait Anxiety Inventory (STAI) were used as assessment tools.

Results: The results of this study indicate that mothers of disabled children have statistically significantly higher scores on the ASDA subscale of "fear related to other situations reminding death" than mothers of non-disabled children. Similarly, mothers of disabled children have significantly higher state and trait anxiety levels.

Conclusion: Mothers of disabled children have higher death anxiety and state-trait anxiety levels than mothers of non-disabled children. These results suggest that having a disabled child increases mothers' psychological burden. We may assume that psychological support provided for mothers with disabled children will improve the quality of care they give to their children and consequently increase the quality of life of children and family.
\end{abstract}

Keywords: Death anxiety, disabled, mother, state anxiety, trait anxiety.

\section{INTRODUCTION}

There is a variety of definitions for "disability," but generally speaking, we could say that it refers to the failure of one or more organs in the body to fulfill its function. The Turkish Language Association explains the term using the expression "a disabled, hampered, person or one with bodily deficiencies or defects" (1). Originating before, during, or after birth for any reason, it can affect language and speech, hearing, intellectual faculties, sight, or neuromuscular functioning (2).

The term "anxiety," meaning a loss of breath or choking, can be described as an unreflective but sensed state of emotion (3). State anxiety represents an unpleasant affective state of unease, discomfort, and nervousness resulting from a person's perception of their present state as being dangerous and threatening (4). As state anxiety is a subjective fear, its level increases

How to cite this article: Koca A, Basgul SS, Yay M. Comparison of Death Anxiety and State-Trait Anxiety Levels in Mothers of Disabled Children and Non-Disabled Children. Dusunen Adam The Journal of Psychiatry and Neurological Sciences 2019;32:58-64.

Correspondence: Saziye Senem Basgul, Hasan Kalyoncu University, Faculty of Medicine, Department of Psychology, Havaalani Yolu Uzeri, 8. km., Sahinbey, Gaziantep, Turkey

Phone: +90 21254365 65/2731 E-mail: senembasgul@gmail.com

Received: March 12, 2018; Revised: March 22, 2018; Accepted: November 12, 2018 
in stressful situations and decreases as stress resolves (5). Trait anxiety refers to a person's susceptibility for experiencing anxiety, a disposition for anxiety, where state anxiety becomes more intense and continuous. The perception of stressful situations as dangerous and threatening then leads to increasingly more frequent state-affective responses to these threats reaching the level of continuity. Given the interpersonal differences, it can be considered a personal trait. Individuals with high trait anxiety tend to perceive stressful situations as more dangerous or threatening than other people and give a more intense response (6).

Emotions, fears, and thoughts underlying normal life experiences that are related to the end of life are called death anxiety (7).

All parents want their children to be physically and cognitively perfect. Some children are born with special needs, and their parents are struggling throughout their lives to prepare them for the future in the best possible way and to avoid problems they might encounter later in life (8). The birth of a disabled child leads to certain changes in family life. Right after birth, families do not know what to do, where to go, who to tell what and what questions to ask. Overwhelmed by these unknowns, they may get confused (9). Families with disabled children often do not know how to cope with their children's state, are worried for their future, and tend to accuse themselves of being the cause of their children's disabilities. In addition, social support may be insufficient (10). From the moment of a disabled child's birth, the mother finds herself being responsible for the child's care and upbringing, in addition to other problems. According to Ozturk (11), the experiences of the family members, and the mother's in particular, develop through a sequence of "shock, disbelief and denial, anger and rage, bargaining, excessive grief and depression, guilt, inability to accept, reconciliation, acceptance, and adaptation". The problems experienced after the birth of a disabled child and the future uncertainties can also have a negative impact on the attachment process between child and mother, and the resulting difficulties may increase the mother's anxiety (12).

Mothers of disabled children report that, in addition to the disappointment felt at childbirth, they are intensely anxious due to problems with special care and therapy, and they do not receive sufficient social, psychological, and economic support while struggling with these issues (13). A study comparing mothers of healthy children with mothers of children with intellectual disabilities found a higher level of emotional burnout among the mothers of the disabled children.
Factors found to be related with the emotional exhaustion of mothers with intellectually disabled children were "personal success, cognitive affective factors, a helpless approach, and search for social support" (14).

Semi-structured interviews with mothers of children with multiple disabilities found that the mothers complained of insomnia, fatigue, and back pain and showed a high level of anxiety (15). A qualitative study with the mothers of 20 children with spina bifida identified four relevant themes: "living with constant anxiety, living with uncertainty, living with a burden, and living with a difficult life situation" (16). Having a disabled child not only increased parents' stress, anxiety, and worry levels but also reduced expectations related to the children's future (17).

Although in Turkey, as in the rest of the world, societal awareness for the disabled increases, their relatives can still remain on their own when trying to cope with the difficulties they experience. As an addition to the existing literature about negative emotions experienced by relatives of disabled persons, this study aims to test the hypothesis that in mothers of disabled children, death anxiety and state-trait anxiety levels are higher than in mothers whose children are not disabled. We then assess the relation between the anxiety of mothers with disabled children and factors like the child's sex, the parents' level of education and profession, the identity of the caregiver, and the socioeconomic situation of the family.

\section{METHOD}

Data collection for the study was carried out between February and April 2017. The study population consisted of the mothers in the central district of Sehitkamil in the province of Gaziantep. We used a causal-comparative study design and a convenience sampling method. The study sample consisted of a total of 158 mothers: 80 women with disabled children attending two special education and rehabilitation centers in Sehitkamil who were approachable and accepted to participate in the study and 78 mothers with non-disabled children living in the same district who volunteered to participate. In the process, participants were orally informed about the purpose of the study, and those who volunteered were included in the study upon giving their consent. The data collection instruments specified below were individually administered by the researcher to the mothers who were waiting their children at the institution. 
It took about 25 minutes for the participants to complete the form and the scales. In view of the basic purpose of this study, data of all mothers with and without disabled children were used. When testing the differences according to other sociodemographic factors, however, only the data for the mothers of disabled children were used. Ethics approval for the study was obtained from the Ethics Committee of Hasan Kalyoncu University.

\section{Data Collection Instruments}

For this study, a sociodemographic form prepared by the research team and two different scales were used: the Arabic Scale of Death Anxiety and the State-Trait Anxiety Inventory.

Sociodemographic Data Sheet: Prepared by the research team specifically for this study, the form included questions about age, sex, mother's and father's educational and employment status, economic status, the kind of disability the child suffered from, and who was caring for the disabled child.

Arabic Scale of Death Anxiety (ASDA): The scale was developed by Abdel-Khalek (18) and adapted to Turkish by Aydogan et al. (19). It has a Cronbach's alpha value of 0.86 . The ASDA consists of 20 items with response choices on a 5-point Likert-type scale: 1 - No, 2 - A little, 3 - A fair amount, 4 - Much, and 5 - Very much. The scale contains the following subdimensions, with the items being distributed as listed: factor 1 "fear elicited by death-related visual stimuli (items $2,8,11$, $16,17)$, factor 2 "fear of physical and mental suffering coming with death" (items 5, 6, 10, 15, 19), factor 3 "fear related to other situations reminiscent of death" (items 3,12, 14, 18), factor 4 "fear of postmortem events" (items $7,9,13$ ), and factor 5 "fear regarding the process of death" (items 1, 4, 20).

State-Trait Anxiety Inventory (STAI): The form was developed in 1970 by Spielberger et al. (20) and adapted to Turkish culture with validity and reliability studies by Oner (5). It consists of a 20 -item state anxiety scale and a 20-item trait anxiety scale, thus a total of 40 items. The state anxiety scale describes how the subject feels in a particular moment under specific conditions, asking for answers considering their feelings regarding their situation. The trait anxiety scale establishes how a person feels generally. In the Turkish version, Cronbach's alpha reliability coefficient for the state anxiety scale was between 083 and 0.92 and for the trait anxiety scale between 0.83 and 0.87 , while the internal consistency for the state anxiety had a Cronbach's alpha value of 0.76 and for the trait anxiety scale of 0.87 (5).

\section{Statistical Analysis}

The study data were entered in SPSS to analyze basic descriptive statistics and difference testing. Independent groups t-test was used for sociodemographic characteristics with subgroups having an $n>30$ showing parametric (normal) distribution and consisting of two subgroups; for sociodemographic characteristics consisting of two subgroups, where the subgroups had an $\mathrm{n}<30$ and non-parametric (non-normal) distribution, Mann-Whitney U-test was used; for sociodemographic variables consisting of more than two subgroups, with $\mathrm{n}<30$ and non-parametric (non-normal) distribution, Kruskal-Wallis $\mathrm{H}$-test was applied, and subgroups of variables with a significant difference shown by this test were compared pairwise with Mann-Whitney U-test.

\section{RESULTS}

The sociodemographic characteristics of the total sample of 158 mothers, 80 of whom $(50.6 \%)$ had a disabled child while 78 mothers (49.4) did not have disabled children, are shown in Table 1.

In the independent groups t-test carried out to test the differences in the levels of death anxiety subdimensions between mothers with and without disabled children, a statistically significant difference was only found in the subdimension "fear related to other situations reminiscent of death," with higher values for mothers of disabled children $(p=0.014$; $t=2.50 ; \eta^{2}=0.199$ ); in the other subdimensions, no

Table 1: Sociodemographic characteristics of the sample

Subgroup n $\%$

Interviewed mother has disabled child

Yes

No

Interviewed mother's educational status

$\begin{array}{lll}\text { Only literate } & 20 & 12.7 \\ \text { Completed primary/middle school } & 58 & 36.7 \\ \text { High school diploma } & 39 & 24.7 \\ \text { Graduate/postgraduate degree } & 41 & 25.9\end{array}$

Who is looking after the disabled child?

$\begin{array}{lcc}\text { Mother herself } & 109 & 69 \\ \text { Relatives } & 20 & 12.7 \\ \text { Paid care worker } & 16 & 10.1 \\ \text { Other } & 13 & 8.2 \\ \text { nder of the disabled child } & & \\ \text { Female } & 37 & 23.4 \\ \text { Male } & 43 & 27.2\end{array}$


statistically significant difference was established $(\mathrm{p}>0.05)$ (Table 2).

Results of the independent groups t-test performed to test the differentiation of state-trait anxiety levels between mothers with and without disabled children showed a statistically significant difference of both state and trait anxiety dimensions in the direction of mothers with a disabled child $(\mathrm{p}<0.001)$ (Table 3$)$.

A comparison of the death anxiety and state-trait anxiety levels in mothers with disabled children according to the child's sex, using independent groups t-test, found no difference in the scores for death anxiety subdimensions related to the child's sex, while the scores for state and trait anxiety in mothers with a disabled son were statistically significantly higher than in mothers with a disabled daughter $(\mathrm{p}<0.05, \mathrm{p}<0.01$, respectively).

Results of the Kruskal-Wallis H-test used to test the differentiation of death anxiety and state-trait anxiety in mothers with a disabled child according to the mother's level of education showed a statistically significant difference in the death anxiety subdimension "fear of postmortem events" derived from the mothers' level of education $(\mathrm{p}<0.05)$. Mann-Whitney U-test found that values were greater in elementary/middle school graduates compared to only literate mothers and also greater in elementary/middle school graduates when compared to high school graduates. No significant differences were established between the other subgroups. For the state and trait anxiety scores, no statistically significant difference was found according to level of education.

Results of the Kruskal-Wallis $\mathrm{H}$-test used to assess the effect of the father's profession on the level of death anxiety in the mother of a disabled child showed a statistically significant correlation for the subdimensions "fear of physical and mental suffering coming with death" and "fear of postmortem events" ( $\mathrm{p}<0.01, \mathrm{p}<0.05$, respectively); however, for the subdimensions "fear elicited by death-related visual stimuli," "fear related to other situations reminiscent of death," and "fear regarding the process of death," no significant difference was found. According to the Mann-Whitney U-test used to establish between which subgroups a difference exists, values were statistically significantly higher in mothers whose husbands were workers, compared to husbands being managers, civil servants, or members of other professional groups $(\mathrm{p}<0.05)$.

No statistically significant correlation was found between the disabled child's father's profession and the mother's state and trait anxiety scores.

Regarding the duration of special education and the mothers' death anxiety, scores in the subdimension "fear of physical and mental suffering coming with death" for mothers of disabled children having received more than 3 years of special education were statistically significantly higher than for mothers of disabled children with 1 year of special education $(\mathrm{p}<0.01)$.

For the correlation between the variable of childcare by the mother herself, relatives, or a paid caregiver and death anxiety, no statistically significant difference was found. In relation to trait and state anxiety, the lowest state anxiety score was found in mothers looking after the children themselves, whereas no statistically significant difference was found in the trait anxiety scores $(\mathrm{p}<0.05)$.

Table 2: Comparison of the subdimensions of death anxiety between mothers with and without a disabled child

\begin{tabular}{|c|c|c|c|c|c|c|}
\hline & \multicolumn{2}{|c|}{$\begin{array}{l}\text { Disabled group } \\
(\mathbf{n}=\mathbf{8 0})\end{array}$} & \multicolumn{2}{|c|}{$\begin{array}{l}\text { Non-disabled } \\
\text { group }(n=78)\end{array}$} & \multirow[b]{2}{*}{$\mathbf{t}$} & \multirow[b]{2}{*}{$\mathbf{p}$} \\
\hline & Mean & SD & Mean & SD & & \\
\hline "Fear elicited by death-related visual stimuli" & 3.12 & 0.99 & 2.90 & 1.07 & 1.31 & 0.192 \\
\hline $\begin{array}{l}\text { "Fear of physical and mental suffering coming with } \\
\text {...." }\end{array}$ & 3.41 & 0.97 & 3.41 & 0.91 & 0.05 & 0.961 \\
\hline "Fear related to other situations reminiscent of death" & 2.53 & 1.01 & 2.14 & 0.94 & 2.50 & 0.014 \\
\hline “Fear of postmortem events" & 3.41 & 1.02 & 3.20 & 1.12 & 1.22 & 0.226 \\
\hline "Fear regarding the process of death" & 2.71 & 0.92 & 2.59 & 1.06 & 0.72 & 0.471 \\
\hline
\end{tabular}

Table 3: Comparison of state-trait anxiety levels between mothers with and without a disabled child factor

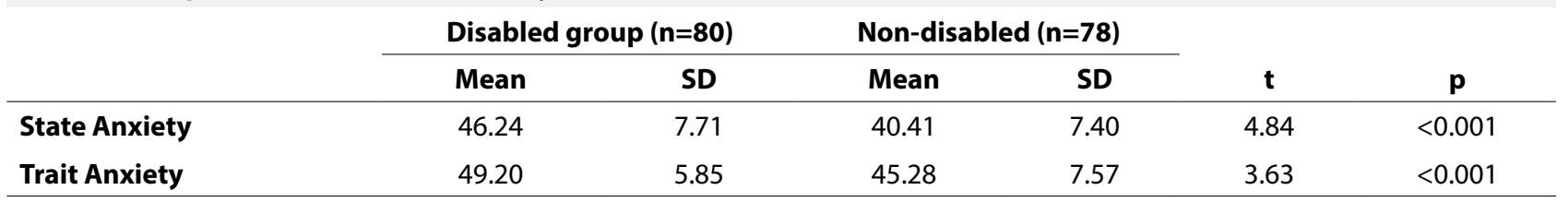


In our study, we classed the expectations for the future of the disabled according to the answers given to the question "do you assess your expectations for the future of your child as good, bad, or none." No statistically significant difference in the mothers' death anxiety or trait anxiety scores was found between the three groups. Mothers with positive expectations for the future of their disabled child had statistically significantly lower state anxiety that mothers with negative or no expectations $(\mathrm{p}<0.01)$.

Death anxiety in mothers with disabled children having a comorbidity was statistically higher than in mothers of disabled children without another ailment, but only in the subdimension "fear of physical and mental suffering coming with death" $(\mathrm{p}<0.01)$.

No statistically significant difference deriving from the absence of other ailments in the disabled on the mothers' state and trait anxiety scores was found.

Kruskal-Wallis H-test was carried out to test if the death anxiety and state-trait anxiety levels of mothers with disabled children varied according to the mother's profession, income level, number of children, age at diagnosis of disability, the disabled child's attending school, availability of psychological support at home, relationship between the disabled child and their siblings, or with the availability of childcare support; no statistically significant differences were detected between these subgroups ( $\mathrm{p}>0.05$ ).

The result of the Mann-Whitney U-test used to test if the death and state-trait anxiety levels of mothers with disabled children varied according to the mother's marital status, the presence of other disabled persons among the family members, birth order of the disabled child, loss of the child's mother or father, or consanguinity of mother and father, found no statistically significant difference for any of the subgroups $(\mathrm{p}>0.05)$.

\section{DISCUSSION}

Our study shows that trait and state anxiety levels and death anxiety in mothers with a disabled child are higher than in mothers who do not have a disabled child; these anxieties do not vary according to the sex of the children, while comorbidities in the children and unemployment of the spouse increase the mothers' death anxiety, and a higher educational level of the mothers reduces these anxieties. Mothers looking after their disabled child themselves have high state anxiety, while having positive expectations for the future reduces their anxiety.
We may think that having a disabled child produces an increase in the mothers' state and trait anxieties. Cengelli (21) reported a difference in burnout and state-trait anxiety scores between mothers of children with a diagnosis of Down syndrome or autism and mothers of children developing normally, which is in line with the results from our study. Two separate studies found that the state anxiety levels in parents with an intellectually disabled child was higher than in mothers who did not have a disabled child $(22,23)$. A study by Avsaroglu (24) compared the anxiety levels of mothers and fathers with an intellectually impaired child and found the anxiety level in the mothers to be significantly higher. In addition to these results, a large number of studies found that the stress level in mothers of intellectually disabled children was higher than in mothers who did not have disabled children (25).

An analysis of the relation between the anxiety levels of mothers with disabled children and the sex of the child found no effect on the mothers' death anxiety, while mothers of disabled sons carried a higher state and trait anxiety than mothers of disabled daughters. Two studies published on this topic report no effect of the disabled child's sex on the mothers' anxiety levels $(26,27)$. Our finding that the mothers of sons were more anxious than the mothers of daughters might be related to the selection of our sample in an Eastern culture, where male children are given greater importance.

Our analysis of the relation between death anxiety and education level in mothers of disabled children found that primary school graduates and only literate mothers were more anxious about postmortem events than high school graduates, which might be interpreted to mean that mothers with a higher level of education felt more secure regarding the future of their children after they themselves will have died. Akturk (26) reported no relation between the educational status of mothers with disabled children and state and trait anxiety; Coskun (27), on the other hand, established that with increasing education level of the mothers, their mental illness levels are decreased. The result of another similar study by Cengelli (21) was that in mothers of children with autism and Down syndrome, anxiety levels decreased with an increasing level of education. Yet, Dogru and Arslan, similar to Akturk's study, found no correlation between mothers' education and anxiety (28).

Among the mothers of disabled children whose husbands did not work, "fear of physical and mental suffering coming with death" was greater than in mothers whose husbands worked. Mothers whose husbands were 
workers showed a greater "fear of postmortem events" than those whose husbands were civil servants, managers, or belonged to other professions. Akturk (26) reported that in families with an unemployed father, parents' trait anxieties were elevated, whereas no relation was found between state anxiety and the father's profession. It may be normal that the father's profession affects the disabled child's current and future social living and care conditions, and this situation may be reflected in the mother's anxiety level.

Regarding the variable of special education and the mothers" death anxiety, the "fear of physical and mental suffering coming with death" was greater in mothers with a disabled child receiving more than 3 years of special education than in mothers whose child had attended special education for 1 year. This may be interpreted to indicate that with longer duration of education, the mothers' level of information increases, allowing her to confront the potential effects of the disability more realistically: While hopes may have been greater at the beginning of the education, these hopes may have been reduced as the process went on. This topic needs to be investigated in more detailed studies.

We found that the mothers looking after their disabled child themselves had a higher level of state anxiety than those who had someone else to care for the child. Disability affects a person's future and creates the necessity to have a caregiver. Studies indicate that disabled children are mostly cared for by their mothers (29). We can assume that due to concerns about the care of their disabled children, mothers do not leave their care to other people. The levels of stress, depression, and anxiety in mothers of disabled children may also be caused by caring for the children themselves (30). Similarly, in our study we found higher anxiety levels in mothers looking for their disabled children themselves.

With regard to the expectations for the future of the disabled children, we found that mothers with positive expectations for their child had a lower level of state anxiety, while mothers with low or no expectations had high state anxiety scores. When mothers have positive expectations for the future of the disabled child, their state anxiety decreases. Studies have shown that mothers of disabled children have low expectations for the future (31). Avsaroglu et al. (32) showed a significant correlation between the anxiety levels of parents with disabled children and hopelessness. In line with the literature, our study found lower anxiety levels in mothers with positive expectations for their child's future.
Assessing the role of comorbidities in the disabled children, we found those to be a variable leading to an increase in the mothers' "fear of physical and mental suffering coming with death." It has been reported that diseases increase death anxiety (33). Our result could be interpreted to mean that comorbidity in the disabled child is a factor reminding the mother of death.

An important limitation of our study is that we did not enquire if the volunteers had any physical or mental disease. In future studies, it will be important to keep this question in mind.

Finally, anxieties, especially death anxiety, of mothers with disabled children are high. The level of anxiety decrease with a higher education level of the mothers, positive expectations for the future, and an increase of their husbands' work-related qualifications. We believe that our data can provide scientific guidance for the planning of national policies, to include approaches supporting the mothers of disabled children and reduce the uncertainties for the future of disabled persons.

\begin{tabular}{|c|c|c|}
\hline \multicolumn{2}{|c|}{ Contribution Categories } & \multirow{2}{*}{$\begin{array}{l}\text { Author Initials } \\
\text { A.K. }\end{array}$} \\
\hline \multirow{3}{*}{ Category 1} & Concept/Design & \\
\hline & Data acquisition & A.K. \\
\hline & Data analysis/Interpretation & A.K. \\
\hline \multirow{2}{*}{ Category 2} & Drafting manuscript & A.K. \\
\hline & Critical revision of manuscript & S.S.B. \\
\hline Category 3 & Final approval and accountability & S.S.B. \\
\hline \multirow{2}{*}{ Other } & Technical or material support & M.Y. \\
\hline & Supervision & S.S.B. \\
\hline
\end{tabular}

Ethics Committee Approval: Ethics approval for the study was obtained from the Ethics Committee of Hasan Kalyoncu University.

Informed Consent: The study was conducted on a voluntary basis and those who agreed to participate in the study were included in the study. Verbal consent was obtained but no written informed consent was obtained.

Peer-review: Externally peer-reviewed.

Conflict of Interest: There is no conflict of interest between the authors.

Financial Disclosure: None declared.

\section{REFERENCES}

1. Turkish Language Association. Dictionary of Contemporary Turkish, entry "engelli" http://www.tdk.gov.tr. Accessed March 5, 2018. (Turkish)

2. Prime Minister's Office. Basic Indicators for Disability Research in Turkey. Ankara: Basbakanlik Ozurluler Idaresi Baskanligi, 2010. (Turkish)

3. Heidegger M. Being and Time. Yardimli A (Translation Editor) Istanbul: Idea Yayinlari, 2004. (Turkish) 
4. Spielberger, CD. Theory and Research on Anxiety. In Spielberger CD (Editor). Anxiety and Behavior. New York: Academic Press, 1966, 3-23.

5. Oner N, LeCompte A. Handbook for the State-Trait Anxienty Inventory. Istanbul: Bosphorus University Publishers, 1983. (Turkish)

6. Ozguven IE. Psychological Tests. Second ed., Ankara: PDREM Yayinlari, 1998.

7. Langs R. Death anxiety and clinical practice. London: Karnac Books, 1997.

8. Ravindranadan V, Raju S. Adjustment and attitude of parents of children with mental retardation. Journal of the Indian Academy of Applied Psychology 2007; 33:137-141.

9. Mowbray C, Schwarz S, Bybee D, Spang J, Rueda-Riedle A, Oyserman D. Mothers with a mental illness: stressors and resources for parenting and living. Fam Soc 2000; 81:118-129.

10. Okanli A, Ekinci M, Gozuagca D, Sezgin S. Psychsocial problems experienced by the families with intellectually disabled children. Journal of Human Sciences 2004; 1:1-5. (Turkish)

11. Ozturk Y. The Determination of the Needs and Burdens for the Families which has Handicapped Children. Postgraduate Thesis, Halic University Institute for Health Sciences, Istanbul, 2011. (Turkish)

12. Basgul SS. Attachment process in the disabled child. 23. National Congress for Child and Adolescent Mental Health and Diseases Edirne, Abstract Book, 2013, 25. (Turkish)

13. Karadag G. Hardships undergone by mothers with handicapped children, hopelessness and social support from family. TAF Preventive Medicine Bulletin 2009; 8:315-322. (Turkish)

14. Duygun T, Sezgin N. The effects of stress symptoms, coping styles and perceived social support on burnout level of mentally handicapped and healthy children's mothers. Turkish Journal of Psychology 2003; 18:37-52. (Turkish)

15. Dri KM, Yaya I, Zigoli R, Endemel Ayabakan F, Ipou SY, Lambert Moke B. Impact of children with multiple disabilities on families in Abidjan. Sante Publique 2018; 30:135-141. (French)

16. Nahal MSH, Wigert $\mathrm{H}$, Imam A, Axelsson AB. From feeling broken to looking beyond broken: Palestinian mothers' experiences of having a child with Spina Bifida. J Fam Nurs 2017; 23:226-251.

17. Deniz ME, Dilmac B, Aricak OT. An analysis of life satisfaction and state-trait anxiety of theparents with handicapped children. Journal of Human Sciences 2009; 6:953-968. (Turkish)

18. Abdel-Khalek AM. The Arabic scale of death anxiety (ASDA): Its development, validation, and results in three Arab countries. Death Studies 2004; 28:435-457.

19. Saricicek Aydogan A, Gulseren S, Ozturk Sarikaya O, Ozen C.
Reliability and Validity of the Turkish Version of Abdel-Khalek's Death Anxiety Scale among College Students. Noro Psikiyatr Ars 2015; 52:371-375. (Turkish)

20. Spielberger CD, Gorsuch RL, Lushene RE. Manual for the statetrait anxiety inventory. Palo Alto CA: Consulting Psychologists Press, 1970

21. Cengelli B. Comparison of the feelings of anxiety, hopelessness, and burnout in mothers having children with autism or Down syndrome. Ege Journal of Education 2009; 2:1-22.

22. Hall SS, Burns DD, Reis AL. Modelling family dynamics in children with fragile X syndrome. J Abnorm Child Psychol 2007; 35:29-42.

23. Glidden LM, Schoolcraft SA. Depression: its trajectory and correlates in mothers rearing children with intellectual disability. J Intellect Disabil Res 2003; 47:250-263.

24. Avsaroglu S. A research on the anxiety levels of parents who have mentally handicapped children. Journal of Human Sciences 2012; 9:533-549. (Turkish)

25. Hastings RP, Beck A. Practitioner review: stress intervention for parents of children with intellectual disabilities. J Child Psychol Psychiatry 2004; 45:1338-1349.

26. Akturk U. Evaluation of anxiety levels and coping strategies of the parents who have handicapped children. Postgraduate Thesis, Inonu University, Institute for Health Sciences, Malatya, 2012. (Turkish)

27. Coskun Y, Akkas G. The relation which [sic] between anxiety level of the mothers who have disabled children and social support. Journal of Kirsehir Education Faculty 2009; 10:213-227. (Turkish)

28. Yildirim Dogru SS, Arslan E. Comparison of trait and state anxiety levels in mothers with a disabled child. The Journal of Institute of Social Sciences 2008; 19:543-553. (Turkish)

29. Yildirim Sari H. Family burden on families of children with intellectual disability. Cumhuriyet University School of Nursing Journal 2007; 11:1-7. (Turkish)

30. Dereli F, Okur S. Determination of the depression level of the families having a handicapped child. The New Journal of Medicine 2008; 25:164-168. (Turkish)

31. Kermanshahi SM, Vanaki Z, Ahmadi F, Kazemnejad A, Mordoch E, Azadfalah P. Iranian mothers' perceptions of their lives with children with mental retardation: a preliminary phenomenological investigation. J Dev Phys Disabil 2008; 20:317-326.

32. Avsaroglu S, Kelesoglu A, Gilik A. In this research, hopelessness levels according to some variables and anxiety states of parents who have special needs children were examined. Elementary Education Online, 2017; 16:1022-1035. (Turkish)

33. Karakus G, Ozturk Z, Tamam L. Death and death anxiety. Archives Medical Review Journal 2012; 21:42-79. (Turkish) 